\title{
Rancang Bangun Model Reflektor Yagi Bolik Terhadap Pengaruh Hasil Penguatan Sinyal Antena
}

\author{
F Trias Pontia Wigyarianto ${ }^{1)}$, Neilcy Tjahjamooniarsih ${ }^{2)}$ dan Fitri Imansyah ${ }^{3)}$ \\ ${ }^{1,2,3)}$ Program Studi Teknik Elektro \\ Jurusan Teknik Elektro, Fakultas Teknik, Universitas Tanjungpura \\ email: ${ }^{1)}$ triaspontia818@gmail.com, ${ }^{2)}$ neilcyte@gmail.com, ${ }^{3)}$ fitriimansyah@gmail.com
}

\begin{abstract}
Abstrak- Perkembangan teknologi yang semakin pesat, memicu manusia untuk mendapatkan kebutuhan sarana dan prasarana yang lebih praktis, mudah dan efisien. Seiring dengan kebutuhan akan informasi jaringan komunikasi, teknologi WLAN merupakan solusi yang terbaik dalam mengatasi masalah jangkauan sinyal untuk daerah yang jauh dengan menggunakan antena Yagi dengan reflector berbentuk Bolic. Dalam penelitian ini akan dilakukan pengujian pada frekuensi $2.4 \mathrm{Ghz}$ untuk meningkatkan daya terima wifi pada proses penerimaan sinyal wireless USBadapter terhadap sinyal wifi. Pengujian antena Yagi Reflector Bolic ini dilakukan pada jarak 80 meter dan 100 meter. Hasil pengukuran nilai level daya terima pada antena yagi reflector bolic untuk sepuluh kali percobaan didapatkan rata-rata sebesar $-69,7 \mathrm{dBm}$ pada jarak 80 meter dan $\mathbf{- 6 5 , 7 5} \mathrm{dBm}$ pada jarak 100 meter. Dari hasil antena yagi dengan reflector berbentuk bolic maka diperoleh nilai penguatan daya (gain) pada jarak 80 meter sebesar 9,15 dBm dan pada jarak 100 meter untuk nilai penguatan (gain) terbaik diperoleh sebesar 37,25 dBm. Dapat dilihat dari nilai penguatan daya (gain) antena yagi dengan model reflector bolic ini telah berhasil dibuat sesuai tujuannya yaitu untuk mengetahui pengaruh hasil penguatan sinyal pada antena.
\end{abstract}

Kata Kunci : Antena Yagi, Reflectorbolic antena, WIFI 2.4 Ghz, Wireless USB Adapter

\section{Pendahuluan}

Sistem telekomunikasi wireless adalah suatu sistem yang menghubungkan antara dua perangkat atau lebih tanpa menggunakan kabel, yaitu menggunakan gelombang elektromagnetik sebagai sarana pengganti kabel. Dan dibutuhkan perangkat berupa antena untuk menunjang terjadinya komunikasi dalam suatu sistem ini. Dalam sistem komunikasi wireless, peranan antena sangat penting yaitu untuk memancarkan dan menerima gelombang elektromagnetik dari suatu perangkat ke perangkat lain. Seperti antena pemancar, dan ada juga antena penerima, sehingga memungkinkan terjadinya komunikasi dalam suatu jaringan wireless tersebut. Salah satu sistem telekomunikasi wireless adalah Antena model reflektor yagi bolik ini berperan sebagai penguat, yaitu antena yang berfungsi sebagai penguat ulang yang bekerja sebagai penerima, maka antena ini ditempatkan pada lokasi yang memiliki kekuatan sinyal yang rendah dan meningkatkan kembali kekuatan sinyal yang ada sehingga menjadi lebih kuat.

Dalam sistem komunikasi wireless peranan antena sangat penting, yaitu untuk meradiasikan gelombang elektromagnetik. Oleh karena itu, diperlukan suatu antena penerima yang mampu bekerja sebagai penerima dan pelepas energi elektromagnetik yang berperan dalam teknologi Wi-Fi. Wifi dikenal dengan teknologi komunikasi Wireless Local Area Networks (WLAN) yang berhubungan dengan standar jaringan Nirkabel Institute of Electrical and Electronics Engineers (IEEE) 802.11. Wifi dapat dioperasikan oleh internet provider atau individu. Namun dengan berkembangnya teknologi saat ini, masih Personal Computer (PC) dan laptop yang tidak terdapat fasilitas wifi, sehingga membuat sebagian pengguna wifi membutuhkan wireless USB adapter untuk membantu menerima sinyal wifi pada komputer atau laptop. Tubagus Irfan Rianto. (2017:1) menyatakan fasilitas wireless USB adapter yang ada saat ini, jarak jangkau yang di capai dari wireless USB adapter tidak cukup luas.

Menurut Mudrik Alaydrus, (2011: 1). Antena adalah sebuah komponen yang dirancang untuk dapat memancarkan dan menerima gelombang elektromagnetik. Antena sebagai alat pemancar (transmitting antenna) adalah sebuah transducer (pengubah) elektromagnetis, yang digunakan untuk mengubah gelombang teruntun di dalam saluran transmisi kabel, menjadi gelombang yang merambat di ruang bebas dan sebagai penerima (receiving antenna) mengubah gelombang ruang bebas menjadi gelombang tertuntun.

Antena Yagi adalah antena directional yaitu antena yang hanya dapat mengambil atau menerima sinyal dari satu arah yaitu depan karena sisi antena yang berada di belakang reflector memiliki gain yang lebih kecil daripada di depan director.Dengan adanya penambahan model reflector, akan membatasi pola radiasi agar tidak melebar kebelakang dan kekuatan pancarannya akan diperkuat ke arah sebaliknya, sehingga dapat terlihat dengan jelas bagaimana perubahan pola pancar antena sebelum dan sesudah penambahan reflector.

\section{Tinjauan Pustaka}

\subsection{Antena}

Antena adalah salah satu perangkat yang mengubah sinyal-sinyal listrik menjadi gelombang elektromagnetik dan memancarkannya ke udara bebas atau sebaliknya menangkap sinyal gelombang elektromagnetik dari udara bebas dan mengubahnya menjadi sinyal listrik. Berdasarkan definisi tersebut maka antena memiliki 3 fungsi pokok, yaitu:

a. Antena berfungsi sebagai konverter. Dikatakan sebagai konverter karena antena tersebut mengubah bentuk sinyal, yaitu dari sinyal listrik menjadi sinyal Antena berfungsi sebagai radiator. Dikatakan sebagai radiator karena antena tersebut memancarkan gelombang elektromagnetik ke udara bebas sekelilingnya. Jika 
sebaliknya antena menerima atau menangkap energi radiasi gelombang elektromagnetik dari udara bebas, maka fungsinya dikatakan re-radiator.

b. Antena berfungsi sebagai impedance matching (penyesuai impedansi). Dikatakan sebagai impedance matching karena antena tersebut akan selalu menyesuaikan impedansi sistem. Sistem yang dimaksud adalah saluran transmisi dan udara bebas. Pada saat antena tersebut bekerja atau beroperasi maka antena akan menyesuaikan inpedansi karakteristik saluran dengan impedansi karekteristik udara. (Widya, 2015).

Secara umum, antena dibedakan menjadi 2 yaitu: antena omnidirectional dan antena directional.

Antena Omnidirectional yaitu jenis antena yang memiliki pola pancaran sinyal ke segala arah dengan daya yang sama. Antena Directionalmerupakan antena yang memancarkan daya ke arah tertentu. Gain antena ini relatif lebih besar dari antena omnidirectional.

\subsection{Antena Yagi Uda}

Antena Yagi dikenal juga sebagai antena arah yang bersifat langsung memancar dan didesain untuk memancarkan gelombang hanya pada satu frekuensi.Antena ini terdiri dari driven, reflektor dan direktor yang dikenal dengan elemen.

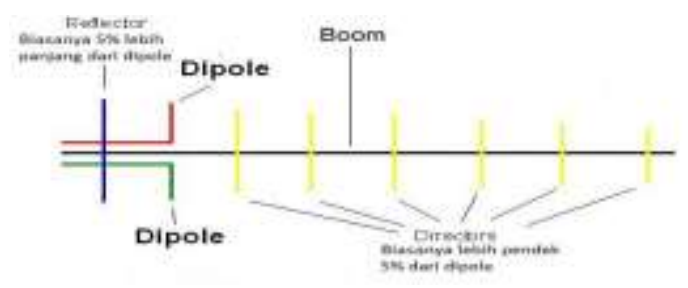

Gambar 1. Antena Yagi Sumber :(Triyadi, 2017)

\section{A. Pengertian Wireless LAN}

Menurut (Widya, 2015) Teknologi Wireless LAN melakukan proses pengiriman data dengan menggunakan frekuensi radio sebagai media perantaranya. Teknologi ini diregulasi oleh aturan yang sama seperti radio AM/FM. Federal Communications Commision (FCC) merupakan organisasi internasional yang meregulasi penggunaan device wireless LAN. Sebaliknya, IEEE (Institute of Electrical \& Electronic Engineers) membuat dan mengelola standardisasi device wireless.

\section{B. Macam-macam frekuensi}

Ada tiga pita (band) frekuensi yang dapat digunakan secara bebas dalam dunia industri, medis, dan ilmiah, antara lain frekuensi $900 \mathrm{MHz}, 2.4 \mathrm{GHz}$, dan 5.2 GHz. Di antara ketiga band, perangkat-perangkat wireless saat ini banyak menggunakan frekuensi 2,4 GHz.

IEEE telah menetapkan protocol standar yang digunakan pada device wireless, yakni:

1. 802.11a, teknologi menggunakan frekuensi $5 \mathrm{GHz}$ dan dapat menghasilkan kecepatan 54 Mbps.

2. $802.11 \mathrm{~b}$, teknologi menggunakan frekuensi $2.4 \mathrm{GHz}$ dan memiliki kemampuan transmisi hingga $11 \mathrm{Mbps}$.

3. $802.11 \mathrm{~g}$, teknologi sama dengan $802.11 \mathrm{~b}$, menggunakan frekuensi $2.4 \mathrm{GHz}$, dan memiliki kemampuan transmisi 54 Mbps.
4. 802.11n, teknologi yang memperbaiki standar 802.11g dalam hal jumlah bandwidth, dan beroperasi 2 frekuensi yaitu $2.4 \mathrm{Ghz}$ dan $5 \mathrm{Ghz}$.

5. 802.11ac, teknologi generasi terbaru mendukung bandwidth mencapai 1300 Mbps pada frekuensi 5 Ghz dan ditambah $450 \mathrm{Mbps}$ pada frekuensi 2.4 Ghz.

\section{METODOLOGI PENELITIAN}

\subsection{Bahan Penelitian}

Bahan penelitian yaitu jaringan internet yang memadai.

1. Alat yang digunakan

a) Perangkat keras

- Laptop Acer E5-475G

- Wireless USB AdapterPerangkat Lunak

b) $T P$-LINK TL-WN722N USB Wireless LAN Utilityini adalah sebuah aplikasi bawaan dari wireless USB adapter.

Adapun beberapa kegunaan dari softwareTP-LINK TLWN722N USB LAN utility adalah sebagai berikut :

- Terdapat nilai signal strength yang indikatornya berupa persentase (\%)

- Terdapat nilai link quality yang indikatornya berupa persentase $(\%)$

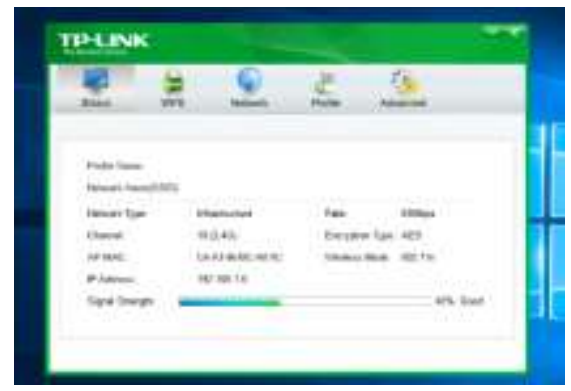

Gambar 2.TampilanTP-LINK TL-WN722N USB Wireless LAN Utility

\subsection{Perancangan Antena Yagi}

Pada perancangan antena Yagi ini, penulis membuat antena yagi dengan model reflector bolic. Di bawah ini adalah gambar desain antena Yagi reflector bolic:

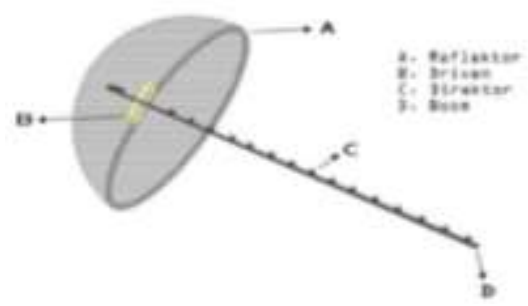

Gambar 3. Rancangan Antena Yagi Bolic

gambar 3. merupakan gambar rancangan antena yagi bolic yang memiliki diameter lingkaran penuh dengan kawat jaring berbentuk parabola.

- Langkah-langkah Perakitan Antena

$>$ Pembuatan Elemen Driven

Potong pipa tembaga sesuai dengan dimensi antena yang diperoleh dari proses perancangan yaitu :

$$
\begin{aligned}
\mathrm{L} & =0,5 \times \mathrm{K} \times \lambda \\
& =0,5 \times 0.95 \times 0.125 \\
& =0,0593 \text { meter } \\
& =5,9 \mathrm{~cm}
\end{aligned}
$$


$\lambda=$ panjang gelombang diudara $(0,125 \mathrm{~m})$

$\mathrm{L}=$ panjang driven $(\mathrm{cm})$

$\mathrm{K}=$ velocity factor pada logam $(0,95)$

Model yang digunakan adalah folded dipole, maka lengkungkan pipa tembaga sehingga seperti gambar di bawah ini.
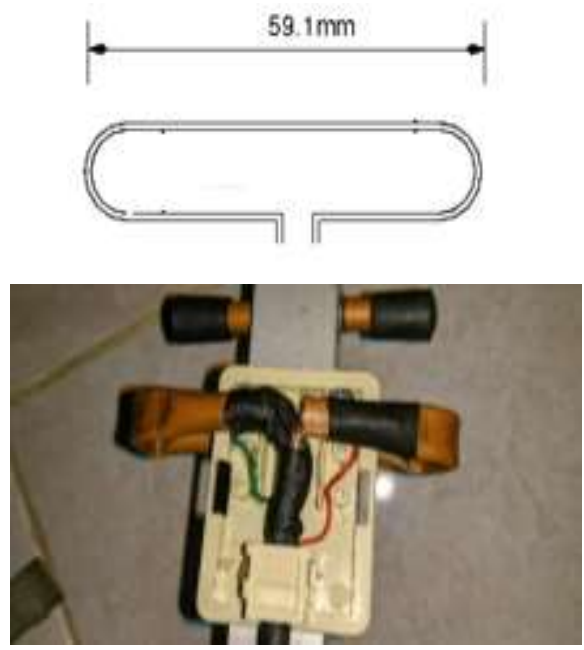

Gambar 4. Elemen Driven

Pembuatan Elemen Direktor

Sama halnya seperti pembuatan elemen driven, elemen direktor juga menggunakan pipa tembaga. Panjang direktor dapat ditentukan dengan :

$$
\begin{aligned}
L_{\text {director }} & =L_{\text {driven }}-5 \%\left(L_{\text {driven }}\right) \\
& =5,9-5 \%(5,9) \\
& =5,9-0,295 \\
& =5.6 \mathrm{~cm}
\end{aligned}
$$
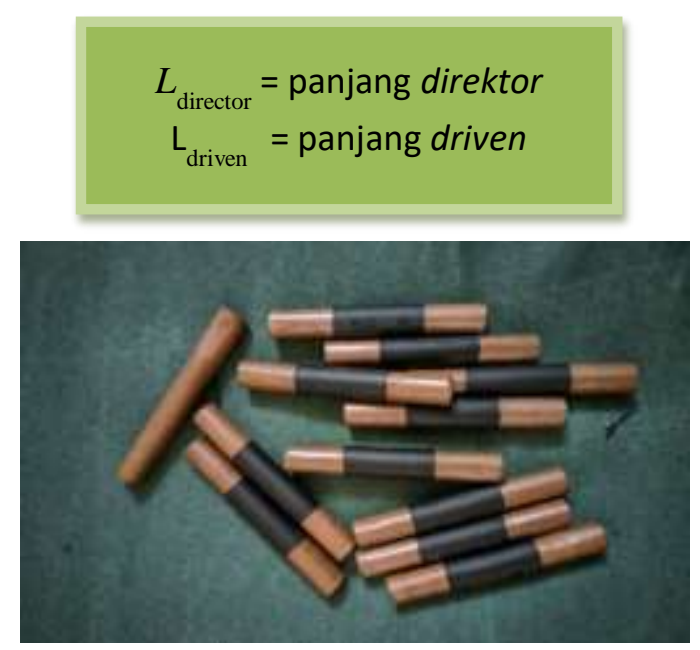

Gambar 5. Elemen Direktor

\section{Pembuatan BOOM}

Potong batang alumunium dengan panjang $54 \mathrm{~cm}$, lalu lubangi menggunakan bor dengan masing-masing jarak
$2 \mathrm{~cm}$ kemudian masukkan elemen driven dan direktor seperti gambar berikut.

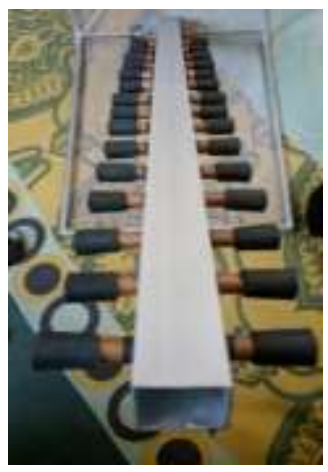

Gambar 6. Proses Pembuatan Boom

\section{Pengambilan Data Pengukuran}

Pengambilan data pengukuran berdasarkan pengujian ditunjukkan pada Gambar 7.
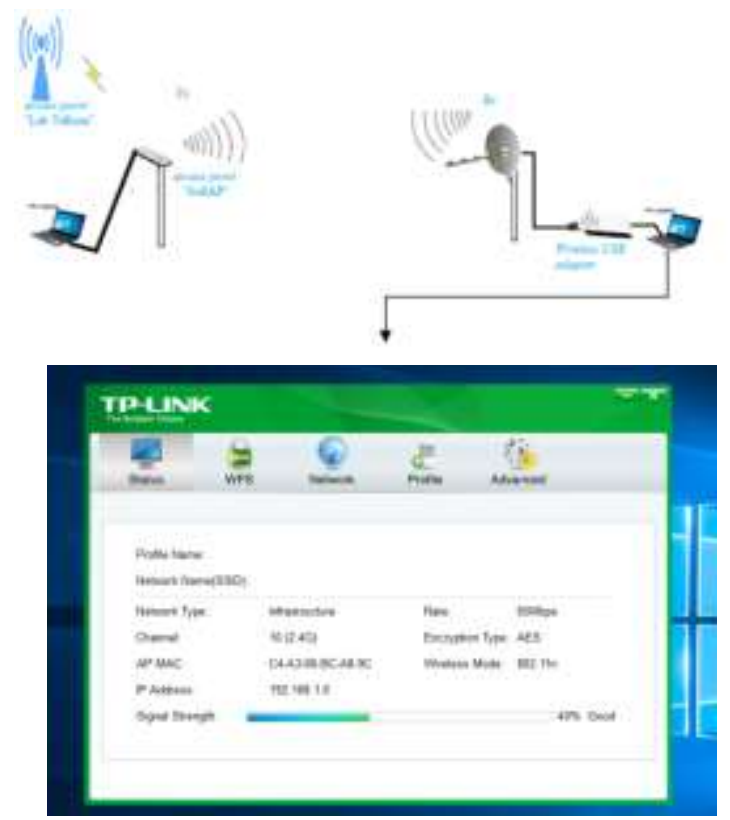

Gambar 7. Skema Pengujian Antena Yagi Sumber : Software TP-LINK TL-WN722N USB Wireless LAN Utility

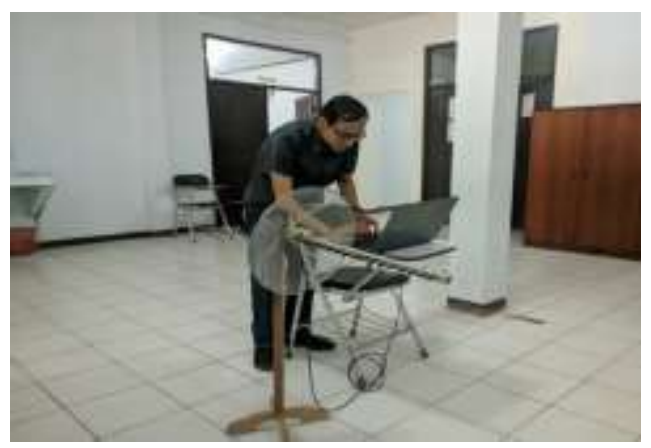

Gambar 8. Proses Pengambilan Data

Gambar 8. merupakan proses pengambilan data dengan menggunakan Software TP-LINK TL-WN722N USB Wireless LAN Utility. Pada pengujian ini dilakukan saat laptop terhubung ke "Access Point". Semua parameter yang 
diperlukan akan dibuktikan dengan screenshot menggunakan software ini.

\section{Hasil dan ANALISIS}

4.1 Perhitungan Daya Pancar dan Daya Terima Antena pada Jarak 80 Meter

Pada pengujian antena Yagi dengan model reflector bolic ini maka akan dilakukan perhitungan sebanyak sepuluh kali percobaan, untuk mengetahui nilai dari daya pancar dan daya terima sebagai berikut.:

$$
\begin{aligned}
P_{R} & =P_{T}-L_{T}+G_{T}-L+G_{R}-L_{R} \\
& =4-1+3-78,06+3-3,125 \\
& =-72,18 \mathrm{dBm}
\end{aligned}
$$

Setelah dilakukan perhitungan, maka nilai daya terima yang didapat adalah $-72,18 \mathrm{dBm}$. Untuk memudahkan pembacaan data dibuatlah Tabel1.

\begin{tabular}{|c|c|c|c|}
\hline $\begin{array}{c}\text { Jenis } \\
\text { Antena }\end{array}$ & $\begin{array}{c}\text { Daya Terima } \\
\text { Perhitungan } \\
(\mathrm{dBm})\end{array}$ & $\begin{array}{c}\text { Daya Terima } \\
\text { Pengukuran } \\
(\mathrm{dbm})\end{array}$ & $\begin{array}{c}\text { Indikator } \\
\text { Warna }\end{array}$ \\
\hline Omni & & $-75,85$ & Good \\
\hline $\begin{array}{l}\text { Yagi } \\
\text { Bolic }\end{array}$ & $-72,18 \mathrm{dBm}$ & $-69,7$ & Excellent \\
\hline
\end{tabular}

Tabel 1. Perhitungan dan Pengukuran Daya Terima pada Jarak 80 meter

Sumber : Hasil Olahan Data

4.2 Perhitungan Daya Pancar dan Daya Terima Antena pada Jarak 100 Meter

Tabel 2.Perhitungan dan Pengukuran Daya Terima pada Jarak 100 meter

\begin{tabular}{cccc}
\hline $\begin{array}{c}\text { Jenis } \\
\text { Antena }\end{array}$ & $\begin{array}{c}\text { Daya Terima } \\
\text { Perhitungan } \\
(\mathrm{dBm})\end{array}$ & $\begin{array}{c}\text { Daya Terima } \\
\text { Pengukuran } \\
(\mathrm{dbm})\end{array}$ & $\begin{array}{c}\text { Indikator } \\
\text { Warna }\end{array}$ \\
\hline Omni & & $\begin{array}{c}\text { Tidak } \\
\text { terdeteksi }\end{array}$ & Poor \\
\cline { 1 - 1 } $\begin{array}{c}\text { Yagi } \\
\text { Bolic }\end{array}$ & $-74,1 \mathrm{dBm}$ & $-65,75$ & Excellent \\
\cline { 3 - 4 } & & & \\
\hline
\end{tabular}

Sumber : Hasil Hasil Olahan Data
4.3 Penguatan Daya (Gain)

Tabel 3. Rekapitulasi Perhitungan Penguatan Daya (Gain).

\begin{tabular}{cccc}
\hline \multirow{2}{*}{ No } & Antena Yagi & \multicolumn{2}{c}{ Jarak } \\
\cline { 3 - 4 } & & $\mathbf{8 0}$ meter & $\mathbf{1 0 0}$ meter \\
\hline 1 & YagiBolic & $9,15 \mathrm{dBm}$ & $37,25 \mathrm{dBm}$
\end{tabular}

Sumber : Hasil Olahan Data

Maka selanjutnya dibuatlah Gambar 9. dan Gambar 10. sebagai grafik hasil pengujian yang telah dilakukan agar terlihat jelas perubahan nilai daya terima (signal strength)serta penguatan daya ( gain) dari setiap antena pada jarak yang berbeda.

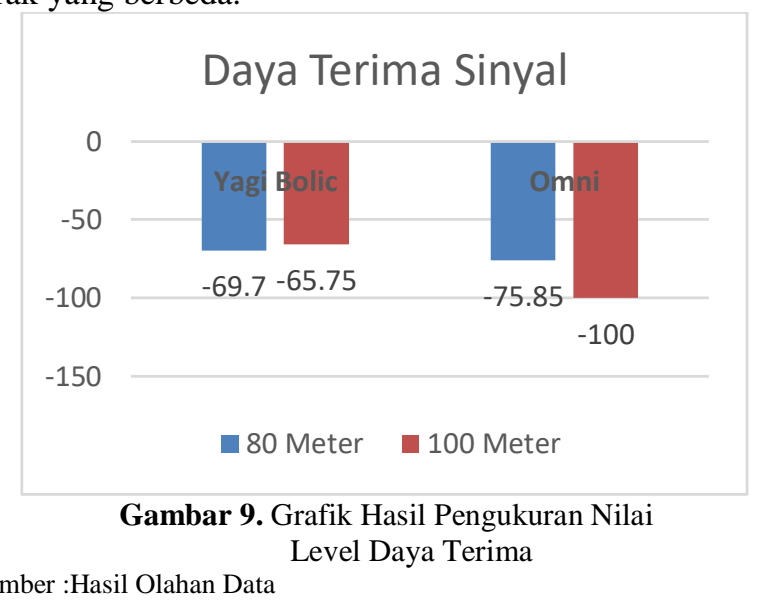

Dari Gambar 9.Grafik di atas dapat dilihat untuk nilai level daya terima yang memiliki tingkat signal strength yang paling baik untuk jarak 80 meter adalah antena Yagi Bolic sebesar $-69,7 \mathrm{dBm}$ dan 100 meter adalah antenaYagiBolic dengan nilai rata-rata sebesar $-65,75 \mathrm{dBm}$. Pernyataan ini telah dibuktikan dalam hasil pengujian di lapangan.

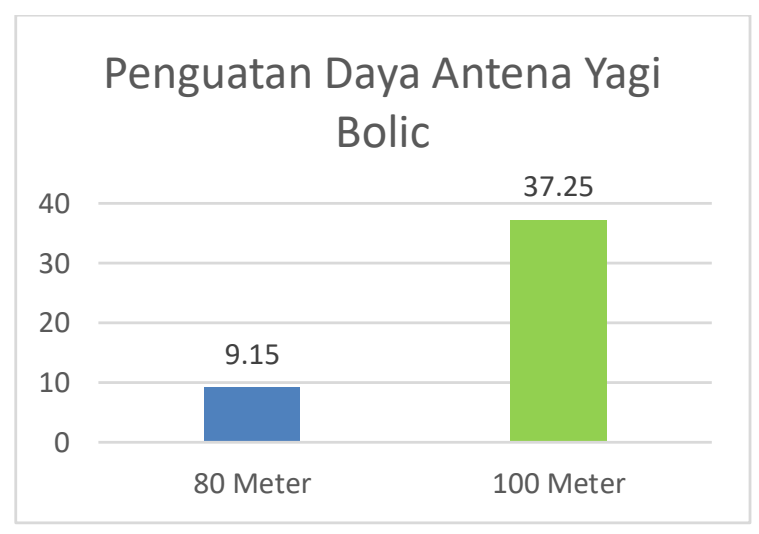

Gambar 10. Grafik Hasil Perhitungan Penguatan Daya (Gain) Sumber : Hasil Olahan Data

Gambar 10. grafik hasil perhitungan penguatan daya (gain) menunjukan bahwa nilai gain pada antena Yagi model reflector bolicini cukup baik. Antena Yagi ini memiliki nilai penguatan yang cukup besar yaitu pada jarak 80 meter memiliki nilai penguatan daya (gain) sebesar 9,15 $\mathrm{dBm}$ dan pada jarak 100 meter memiliki nilai penguatan daya (gain) sebesar 37,25 dBm. Berdasarkan grafik hasil 
pengujian di atas terlihat yang memiliki nilai level daya terima (signal strength) serta penguatan daya (gain) yang paling baik terdapat pada antena Yagi Bolic. Kedua grafik tersebut menunjukan bahwa antena Yagidengan model reflectorbolicini telah berhasil dapat meningkatkan nilai level daya terima pada wireless USB adapter yang bekerja pada frekuensi 2,4 GHz.

\section{KESIMPULAN}

1. Perhitungan dan pengukuran nilai level daya terima menggunakan antena Omni pada jarak 80 meter didapat perhitungan sebesar $-72,18 \mathrm{dBm}$ dan pada jarak 100 meter didapat perhitungan sebesar $-74,1 \mathrm{dBm}$. Untuk hasil pengukuran pada jarak 80 meter didapat dengan rata-rata level daya terima sebesar $-75,85 \mathrm{dbm}$ dengan kategori kualitas sinyal baik (Good), dan untuk jarak yang lebih jauh yaitu 100 meter wirelessUSBadapter TPLINK WN722N sudah tidak dapat terkoneksi pada access point.

2. Hasil pengukuran wirelessUSBadapter dengan menggunakan antena YagiReflector bolic pada jarak 80 meter sebesar $-69,7 \mathrm{dBm}$ kualitas sinyal sangat baik (Excellent).

3. Pengukuran Level daya terima pada jarak 100 meter wirelessUSBadapterTP-LINK WN722N yang menggunakan antena Yagi Reflectorbolicsebesar -65,75 $\mathrm{dbm}$.

4. Berdasarkan hasil rata-rata pengukuran daya terima pada jarak 80 meter menggunakan Antena Omni bawaan wireless USB adapter dan Antena Yagi dengan model ReflectorBolicdibuktikan dengan softwere TP-LINK TLWN722N USB Wireless LAN Utility mendapatkan penguatan daya (gain) pada antena YagiBolic sebesar $9,15 \mathrm{dBm}$.

5. Pada hasil pengujian dengan softwere $T P-L I N K T L$ WN722N USB Wireless LAN Utility pada jarak 100 meter mendapatkan penguatan daya (gain), antena antena Yagi ReflectorBolicsebesar 37,25 dBm.

6. Dari hasil pengukuran dan pengujian dapat dilihat bahwa antena Yagi denganmodel reflectorbolicini telah berfungsi dengan baik, dengan ditunjukan oleh besarnya penguatan daya (gain) untuk jarak 80 meter sebesar 9,15 $\mathrm{dBm}$ dan untuk jarak 100 meter diperoleh nilai terbaik terdapat pada antena Yagi Bolic sebesar 37,25 dBm.

7. Pada pengembangan berikutnya dapat melakukan penelitian dengan merubah ukuran material reflector sehingga dapat meningkatkan penguatan daya (gain) yang lebih baik lagi.

8. Penelitian lebih lanjut dapat dilakukan dengan cara memberi obstacle pada jarak untuk mengetahui perubahan signal strength nya

9. Diperlukan pengecekan, perawatan dan pemeliharaan untuk mendapatkan penggunaan yang lebih lama pada antena ini.

\section{DAFTAR PUSTAKA}

[1] Alaydrus, Mudrik. 2011. Antena Prinsip \& Aplikasi. Yogyakarta: Graha Ilmu.

[2] A.Zulkifli Lubis. 2014. Pengaruh Posisi Antena Terhadap Sinyal Gelombang Antena Yagi Alumunium. Medan: Fakultas teknik Universitas Sumatera Utara (USU).

[3] Firmanto. 2010 "Simulasi Perancangan Antena Yagi Untuk Aplikasi WLAN". Teknik Elektro, Fakultas Teknik, Universitas Sumatra Utara Medan.

[4] Ghali Endar Pratomo. 2017. Pengaruh Material Dalam Perancangan Reflektor Antena Bolic Untuk Meningkatkan Daya Terima WIFI. Pontianak: Jurnal Teknik Elektro Universitas Tanjungpura, Fakultas Teknik Universitas Tanjungpura Pontianak.

[5] Muhammad Teddy Yudhanto. 2009. Rancang Bangun Antena Eksternal Payungbolik 2.4Ghz Untuk Komunikasi Wireless LAN (WLAN). Medan : Jurnal Teknik Elektro Universitas Tanjungpura, Fakultas Teknik Universitas Sumatera Utara.

[6] Widya Mayang Sari. 2015. Rancang Bangun Antena Eksternal Parabolik2,4 Ghz Untuk Komunikasi Wireless $L A N(W L A N)$. Palembang: Politeknik Negeri Sriwijaya.

[7] Slamet Triyadi. 2017. Rancang Bangun Antena Yagi Modifikasi Dengan Frekuensi 2,4 Ghz Untuk Meningkatkan Daya Terima Wireless Usb. Pontianak: Jurnal Teknik Elektro Universitas Tanjungpura, Fakultas Teknik Universitas Tanjungpura Pontianak.

[8] Safriyanda. 2011. Perbandingan Efisiensi Antena Dipole Reflektor Sudut Dengan Berbagai Bahan Pada Frekuensi 2,4 Ghz. Lhokseumawe: Politeknik Negeri Lhokseumawe.

[9] Tubagus Irfan Rianto. 2017. Analisis Rancang Bangun Antena Yagi Dengan Reflector Bolik Sebagai Penguat Daya Tangkap Wireless Usb Adapter Dengan Frekuensi Kerja 2.4 Ghz. Pontianak: Jurnal Teknik Elektro Universitas Tanjungpura, Fakultas Teknik Universitas Tanjungpura Pontianak.

[10] Tito, Tuwono. 2008 "Yagi Antenna Design for Wireless LAN $2.4 \mathrm{GHz}$ " Teknik Elektro, Fakultas Teknologi Industri, Universitas Islam IndonesiaYogyakarta. 